\title{
UMA ANÁLISE QUANTITATIVA DO MERCADO FORMAL E INFORMAL NO NORTE BRASILEIRO: OS CASOS DO TOCANTINS E DO AMAPÁ
}

\author{
A QUANTITATIVE ANALYSIS OF THE FORMAL AND INFORMAL MARKET IN \\ NORTH BRAZIL: The cases of Tocantins and Amapá
}

ANÁLISIS CUANTITATIVO DEL MERCADO FORMAL E INFORMAL EN EL

NORTE DE BRASIL: Los casos de Tocantins y Amapá

\section{Mariane Freiesleben ${ }^{*}$, Alex Pizzio da Silva ${ }^{2}$}

${ }^{1}$ Doutoranda do Programa de Pós-Graduação em Desenvolvimento Regional da Universidade Federal do Tocantins (UFT) - Palmas - Brasil.

${ }^{2}$ Doutor em Ciências Sociais pela Universidade do Vale do Rio do Sinos - Unisinos. Coordenador e professor do Programa de Pós-Graduação de Desenvolvimento Regional da Universidade Federal do Tocantins (UFT). Professor da Universidade Federal do Tocantins (UFT) - Palmas - Brasil.

*Correspondência: mariane@ifto.edu.br; alexpizzio@gmail.com.

\section{RESUMO}

Entre 2012 a 2019 o mercado de trabalho passou por várias transformações, nas Leis e na forma de realizar a abordagem pelos organismos responsáveis por esses dados (IBGE). Neste cenário, faz-se necessário realizar um panorama deste segmento. Este artigo abordará o mercado de trabalho brasileiro, com o intuito de encontrar essas transformações do mercado de trabalho brasileiro no tocante a formalidade e informalidade. Para tanto, serão estimadas as probabilidades dos indivíduos brasileiros nas condições do trabalhador (empregado no setor privado, trabalhador doméstico sem carteira de trabalho assinada, empregador sem CNPJ, conta própria sem CNPJ, trabalhador familiar auxiliar) utilizando os dados da PNAD trimestral, divulgados pelo IBGE, referentes aos anos de 2012 a 2019, destacando os estados do Tocantins e Amapá. Metodologicamente realizou-se uma revisão da literatura relacionada às transformações implementadas no mercado de trabalho neste período, e calculou-se um indicador para a estimativa da variação relativa ou redução percentual deste período no Brasil. Os principais resultados mostram que entre 2012 a 2019 aumentou o número de trabalhadores no mercado informal brasileiro. Além do mais, encontrou-se que a Lei do livre mercado implementada no ano de 2019 ampliou o mercado informal. Os resultados demonstram que mesmo com a implementação das novas Leis não ocorreu troca de posições se setores no mercado de trabalho. Isso significa que apesar da precarização das condições nas relações de trabalho, no Brasil como um todo o cenário mercadológico de trabalho continua o mesmo, embora o Estado do Amapá por meio dos seus dados tenha se destacado inversamente ao resultado do Brasil como um todo.

Palavras-chave: mercado formal, mercado informal, trabalhadores.

\section{ABSTRACT}

Between 2012 and 2019 the labor market underwent several transformations, in the Laws and in the way of approaching the bodies responsible for these data (IBGE). In this scenario, it is necessary to provide an overview of this segment. This article will address the Brazilian labor market, in order to find these transformations in the Brazilian labor market in terms of formality and informality. Therefore, the probabilities of Brazilian individuals in the worker's conditions (employee in the private sector, domestic worker without a formal contract, employer without CNPJ, own account without CNPJ, auxiliary family worker) will be estimated using the quarterly PNAD data, released by the IBGE, referring to the years 2012 to 2019, highlighting the states of Tocantins and Amapá. Methodologically, a literature review related to the transformations implemented in the labor market in this period was carried out, and an indicator was calculated to estimate the relative variation or percentage reduction of this period in Brazil. The main results show that between 2012 and 2019 the number of workers in the Brazilian informal 
market increased. Furthermore, it was found that the Free Market Law implemented in 2019 accentuated the informal market. The results show that even with the implementation of the new Laws there was no exchange of positions if sectors in the labor market. This means that despite the precarious conditions in labor relations, in Brazil as a whole the labor market scenario remains the same, although the State of Amapá through its data has stood out inversely to the result of Brazil as a whole.

Keywords: formal market, informal market, workers.

\section{RESUMEN}

Entre 2012 y 2019, el mercado laboral experimentó varias transformaciones, en las Leyes y en la forma de acercarse a los organismos responsables de estos datos (IBGE). En este escenario, es necesario proporcionar una visión general de este segmento. Este artículo abordará el mercado laboral brasileño, para encontrar estas transformaciones en el mercado laboral brasileño en términos de formalidad e informalidad. Por lo tanto, las probabilidades de los individuos brasileños en las condiciones del trabajador (empleado en el sector privado, trabajador doméstico sin contrato formal, empleador sin CNPJ, cuenta propia sin CNPJ, trabajador familiar auxiliar) se estimarán utilizando los datos trimestrales de PNAD, publicados por IBGE, refiriéndose a los años 2012 a 2019, destacando los estados de Tocantins y Amapá. Metodológicamente, se realizó una revisión de la literatura relacionada con las transformaciones implementadas en el mercado laboral en este período, y se calculó un indicador para estimar la variación relativa o la reducción porcentual de este período en Brasil. Los principales resultados muestran que entre 2012 y 2019 aumentó el número de trabajadores en el mercado informal brasileño. Además, se descubrió que la Ley de Libre Mercado implementada en 2019 acentuó el mercado informal. Los resultados muestran que incluso con la aplicación de las nuevas Leyes no hubo intercambio de posiciones si los sectores en el mercado laboral. Esto significa que a pesar de las precarias condiciones en las relaciones laborales, en Brasil en su conjunto el escenario del mercado laboral sigue siendo el mismo, aunque el Estado de Amapá a través de sus datos ha destacado inversamente al resultado de Brasil en su conjunto

.Descriptores: mercado formal, mercado informal, trabajadores.

\section{INTRODUÇÃO}

Duas segmentações são encontradas no mercado de trabalho, o trabalho formal e o informal. A formalidade possui direitos garantidos ao passo que a informalidade não, e geralmente é exercida por trabalhadores que não conseguem inserir-se no mercado formal e aceitam submeter-se à isenção de direitos e benefícios que existem para proteger o trabalhador formal. Para Ulyssea (2006) é o indivíduo que escolhe em qual segmento irá ficar: formal ou informal, valorizando suas preferências e sempre maximizando sua utilidade, em qualquer setor que esteja trabalhando. E para Rodrigues-Filho (2019) o sentido do trabalho ainda é sobreviver, e é da apropriação da força de trabalho, seja física ou intelectual, que o capitalismo se mante contínuo.
É vasta a bibliografia a respeito do trabalho e com grande variedade de enfoques, como as mudanças ocorridas no mercado de trabalho ao longo dos anos (POLANY, 2000; ANTUNES, 2009; 2018; CASTEL, 2012). Inclusive com relação ao emprego do termo "informalidade" e a formação deste "segmento", do qual foram escolhidos alguns autores (NORONHA, 2003) que publicaram materiais que abordam pontos relevantes e que podem contribuir para o entendimento de pontos que estão relacionados a este estudo.

Para entendermos melhor o que será estudado, é preciso iniciar pelo entendimento do conceito de informalidade que é colocado em discussão no artigo de Noronha (2003). Para tanto, o autor faz um resumo do estabelecimento do código de leis do trabalho estabelecido por Vargas, deduzindo que a partir das décadas de 
1930 e 1940 surgem as noções de formalidade e informalidade no Brasil, e que os mercados e os contratos informais seriam o resultado das rupturas do padrão contratual vigente e único, do formal. Explica também que estas ações representam um problema social, pois o contrato formal permite a construção de uma boa sociedade quando é predominante.

Ademais, muito se tem discutido, recentemente, acerca das modificações provocadas no setor formal e informal com a implementação das leis no $13.467 / 2017$ e a lei ${ }^{\circ}$ 13.874/2019. Passando a ser assunto recorrente nas pautas de discussão sobre a proteção dos trabalhadores, no entanto, faz-se necessário uma análise sob o aspecto de entender a situação antes e após suas efetivações. O mercado informal sempre existiu ao longo do tempo, e foi com o tempo que o Estado passou a perceber a necessidade e importância das questões sociais e principalmente da fragilidade das pessoas que vivem do trabalho (POLANY, 2000; CASTEL, 2012), mas com a prática dessas leis, o mercado de trabalho passa por uma adaptação e de acordo com Castel (2012) o oficio desenha a linha divisória entre os incluídos e excluídos do sistema social. E é sempre bom lembrar que a informalidade se expressa de forma multifacetada (RASLAN, 2019).

Não obstante, ao se averiguar os dados do IBGE (2019) divulgados no dia 05/12/2018 e que tem como base informações da Pnad (Pesquisa Nacional por Amostra de Domicílios) revelam que logo após a Lei $\mathrm{N}^{\mathrm{o}} 13.467$ entrar em vigor, ocorreu uma queda acentuada no número de empregos formais e com isso, o crescimento da informalidade no Brasil, que de acordo com o órgão vinha caindo aos poucos desde 2012. A pesquisa supracitada evidencia um aumento do setor informal, e a intenção deste estudo é averiguar por meio dos dados da Pesquisa Nacional por Amostra de Domicílios (PNAD), realizada pelo Instituto Brasileiro de Geografia e Estatística (IBGE), de 2012 a 2019.

Antunes (2018, p.156) alerta que "o entendimento cuidadoso dessa tendência à informalidade nos leva a buscar uma melhor compreensão da chamada terceirização". Que de certa forma aumenta dos diversos modos de ser da informalidade e da precarização (ANTUNES, 2018). E para atingir o objetivo proposto, o artigo encontra-se assim estruturado: além destas considerações iniciais, a segunda seção aborda as novas leis implementadas; em seguida na terceira seção, tecem-se as considerações metodológicas necessárias ao desenvolvimento do trabalho; na quarta seção, apresentam-se a variação do indicador de participação no mercado informal e informal; em seguida, introduz-se o indicador de participação no setor formal e informal dos Estados do Amapá e Tocantins; ademais na sexta seção, faz-se as considerações finais.

\section{LEIS IMPLEMENTADAS}

Segundo Noronha (2003), o mercado de trabalho e a "informalidade" são resultados da formalidade, que está associada às normas de cidadania e direitos sociais. Para o autor, a CLT (Consolidação das Leis do Trabalho, legislação trabalhista brasileira) é um: 
[...] código de trabalho legítimo a ponto de influenciar as práticas do contrato 'informal' e ao mesmo tempo incapaz de instituir parâmetros mínimos que orientem a legitimidade dos contratos de trabalho (NORONHA, 2003, p. 122).

E Antunes (2009), alerta que hoje mais de $50 \%$ da classe trabalhadora no Brasil encontra-se na condição de informalidade, concebida por ele no sentido amplo, desprovida de direitos, fora da rede de proteção social e sem carteira de trabalho. Para o autor o desenho mais frequente de nossa classe trabalhadora é fruto de um desemprego ampliado, de uma precarização exacerbada, de um rebaixamento salarial acentuado, e com perdas crescentes dos direitos.

Em suas obras os autores buscaram destacar a natureza histórica e estrutural, da composição existente da informalidade, bem como as mudanças pelas quais passou ao longo dos anos o mercado de trabalho e as Leis trabalhistas no Brasil. Antunes (2018) vai ainda além, quando expõem que a reforma trabalhista Lei 13.467, desfigurou em definitivo a CLT, induzindo o trabalhador ao trabalho intermitente, assim também como as flexibilizações e as terceirizações contribuíram e contribuem para o aumento da informalidade, em um momento que o desemprego não para de crescer.

A Lei 13.467 foi promulgada em julho de 2017, com um profundo conjunto de alterações nos dispositivos da CLT, entrou em

\footnotetext{
1 Pessoa jurídica representa um sujeito abstrato. Em linhas gerais, a pessoa jurídica é uma entidade que reúne pessoas e patrimônio com uma finalidade, que pode ser prestar um serviço, produzir um bem ou vender um produto. São exemplos as empresas, as associações, as fundações, os partidos políticos, as
}

vigor 120 dias depois, sob a alegação de inserir o país na reestruturação produtiva, e na lógica do capital globalizado, financeirizado, processo típico de governos neoliberais. Esta nova legislação trabalhista refere-se a todas as categorias regidas pela CLT, e também as profissões que dispõem de legislações específicas, como trabalhadores domésticos, atletas profissionais, artistas, advogados aeronautas e médicos, sempre que for pertinente (ANTUNES, 2018).

E posteriormente temos a Lei $\mathrm{n}^{\circ} 13.874$, de 20 de setembro de 2019, da Liberdade Econômica, na qual ficou instituída a declaração dos direitos, as normas de proteção a livre iniciativa e o livre exercício da atividade econômica, em que o Estado passa a agir como agente normativo e regulador. De acordo com a própria Lei a intenção principal seria desburocratizar e simplificar os processos relacionados às empresas e empreendedores, como também flexibilizar algumas regras trabalhistas. Esta Lei dispensa alvará e licenças para funcionamento de pessoas jurídicas ${ }^{1}$, ou seja, precisa de um Cadastro Nacional de Pessoa Jurídica (CNPJ), e ou ter uma inscrição municipal e ou estadual somente, para ser considerado um empreendedor. Ações consideradas por alguns autores como incentivo a "informalidade" (ANTUNES, 2009, 2018; CASTEL, 2012).

igrejas, as administrações públicas, dentre outros. Ainda que seja formada por uma ou mais pessoas físicas, que são as responsáveis pela entidade criada, a pessoa jurídica possui uma personalidade jurídica independente e diferenciada em relação a cada um de seus membros. 
Sobre o tema em questão Corseuil; Nery; Ulyssea (2016) destacam que ainda em 2008, o Governo criou uma política denominada MEIs - Micro Empreendedores Individuais, voltada para os setores de empreendedores não inscritos no Cadastro Nacional de Pessoa Jurídica (CNPJ), para isso reduziu significativamente os custos, incentivando a criação de empresas individuais, visando a formalização de empreendimentos e a geração de empregos formais, isso porque os empreendedores que não possuem CNPJ não contribuem para o sistema previdenciário, ficando desprotegido pelo sistema de seguridade social, contribuindo também para a evasão fiscal.

Os MEIs - Microempreendedores individuais, são profissionais autônomos, que trabalham por conta própria, cujas atividades de acordo com a Lei Complementar 123/2006, e alterado pela LC 155/2016 passam a ter suas atividades legalizadas. O MEI foi criado pela Lei Complementar 128/2008, e nesse sistema o microempresário individual não pode ter sócios, podendo ter no máximo um funcionário, a receita bruta anual pode chegar até $\mathrm{R} \$ 81 \mathrm{mil}$ (valor que entrou em vigor em janeiro de 2018). Este micro empresário passa a ser enquadrado no Simples Nacional e fica isento dos tributos federais (Imposto de Renda, PIS, Cofins, IPI e CSLL). Passa a pagar um valor mensal fixo de $5 \%$ do limite mensal do salário mínimo e mais R\$ 1,00 (um real), a título de ICMS, caso seja contribuinte desse imposto, esta quantia será destinada à Previdência Social e ao ICMS ou ao ISS. Por meio do pagamento destas taxas esse micro empreendedor passa a ter direitos trabalhistas. A que se destacar, ainda, que o Mei prestador de serviço recolhe $\mathrm{R} \$ 5,00$ (cinco reais) a título de Imposto Sobre Serviços que é destinado a prefeitura de seu município (SEBRAE, 2020).

A EI - Empresário Individual, não pode ser confundida com a MEI, pois diferenciam-se em relação à restrição de atividades, ao faturamento anual e ao número de obrigações acessórias. Na EI o empresário também trabalha por conta própria, porém o faturamento anual possui teto máximo de R $\$ 360$ mil, quando é considerado ME (Micro Empresa), ou até 3,6 milhões, sendo EPP (Empresa de Pequeno Porte). Este faturamento anual na forma de tributação é mais abrangente e possui responsabilidades acessórias. Ademais, a pessoa física que se coloca como titular da empresa e responde pelos débitos do negócio, realiza a fusão do patrimônio da empresa e empresário. Assim também como o EIRELI Empresário Individual de Responsabilidade Limitada, ME - Microempresa e EPP Empresa de Pequeno Porte, pois, são regras diferentes e não estão alinhadas nesta proposta do MEI (SEBRAE, 2020).

Oliveira (2019), relata que poucas foram as inovações normativas efetivas na Lei 13.874/2019, como a positivação de regras e princípios que já eram aceitos, pela doutrina e pela jurisprudência majoritária. De acordo com o autor a Lei é fruto de um intenso debate entre parlamentares e escolas acadêmicas, e somente normatizou um mercado que já existia, não atacando os problemas específicos que entravam a livre iniciativa no Brasil. Contudo, essas interpretações deixam de apontar dados 
reais sobre a promoção ou não do setor informal, e de acordo com Lima e Costa (2016), que realizaram uma Revisão Sistemática de Literatura (RSL), de 2004 até 2013 não foi produzida uma quantidade significativa sobre o tema da informalidade, os artigos encontrados utilizavam uma abordagem qualitativa, e o tipo de pesquisa descritiva, prevalecendo a análise do discurso entre os métodos de análise.

Pretende-se por meio deste estudo demonstrar o comportamento do mercado de trabalho, com destaque ao setor informal após a implementação da Lei 13.467/2017 e $13.874 / 2019$, por meio da análise fatorial que apresenta uma visão global de um fenômeno que possui uma abordagem univariada. Para tanto estaremos apresentando os dados referentes ao Brasil e aos Estados do Amapá e do Tocantins, numa análise para responder questões relacionadas ao Projeto PROCAD CONSTRUÇÕES DE ESTRATÉGIAS DE DESENVOLVIMENTO REGIONAL E AS DINÂMICAS TERRITORIAIS DO AMAPÁ E TOCANTINS: 30 anos de desigualdades e complementaridades, tendo em vista o fortalecimento dos estudos relacionados ao Desenvolvimento Regional das áreas estudadas e atendendo aos objetivos específicos de natureza acadêmica: socioeconômicos.

\section{METODOLOGIA}

Os dados utilizados nesse trabalho são trimestrais da PNAD dos anos 2012 até o terceiro trimestre de 2019. Os dados foram trabalhados levando-se em consideração o peso amostral da média de cada ano das observações. A composição da informalidade foi realizada utilizando as condições do trabalhador (empregado no setor privado, trabalhador doméstico sem carteira de trabalho assinada, empregador sem CNPJ, conta própria sem CNPJ, trabalhador familiar auxiliar) que $o$ IBGE passa a considerar a partir de 14 anos ou mais de idade, ocupadas na semana de referência da pesquisa, separando a base de dados em três amostras distintas, o total do Brasil e realiza uma comparação entre os estados do Amapá e do Tocantins. Os resultados empíricos do estudo poderão ser encontrados na sessão 3.

Para o estudo foi utilizado o banco de dados da Pesquisa Nacional por Amostra de Domicílios (PNAD), realizada pelo Instituto de Geografia e Estatística (IBGE). A PNAD abrange a população residente nas unidades domiciliares de todas as Unidades da Federação, Grandes Regiões e Brasil, e é realizada com base em um questionário, com maior ênfase para o trabalho e o tipo de ocupação, respondido pelos indivíduos de acordo com as informações relativas à semana de referência da pesquisa, e apresenta os resultados relativos às características gerais do trabalhador empregado no setor privado, trabalhador doméstico sem carteira de trabalho assinada, empregador sem CNPJ, conta própria sem CNPJ, trabalhador familiar auxiliar. A pesquisa é realizada a fim de gerar um banco de dados variado, e a partir deste, seja possível realizar a avaliação da realidade demográfica e socioeconômica do Brasil.

Foram manuseadas as informações da PNAD referentes ao ano de 2012, período de estabilidade política e econômica do Brasil, e 
sem alterações significativas na Consolidação das Leis do Trabalho (CLT) de forma continua até terceiro trimestre de 2019, dando destaque aos períodos de 2017 e 2019 no qual foram promulgadas as reformas trabalhistas, no entanto, os quesitos Empregador sem CNPJ e Conta própria sem CNPJ só passam a ser computados a partir de 2016 (Ver tabela 01).

As características da amostra apresentadas na tabela 1 , demonstram as estatísticas descritivas, tendo sido agrupado as pesquisas trimestrais de forma anual, na qual foram somados os quatro valores trimestrais do ano, e dividindo por quatro para alcançar uma média anual, de cada ano, dos sete anos analisados pela pesquisa. Contendo pessoas de 14 anos ou mais de idade com variável de mil pessoas. Posteriormente apresenta a variação relativa e ou a redução percentual entre 2012 a 2019.

Desta feita, utiliza-se de indicadores simples, porém oportunos, já que a intenção é mostrar a variação percentual da população ocupada nos setores de ocupação no ano de 2012 como dado anterior e 2019 como dado atual. Destarte, para observar o comportamento dos setores ao longo do período, tem-se que:

$$
\mathrm{A} 19-\mathrm{A} 12=\mathrm{R} 1 / \mathrm{A} 12=\mathrm{R} 2 \times 100=\mathrm{RF} \%
$$

Onde,

A19 = ano de 2019;

A12 = ano de 2012;

$\mathrm{R} 1$ = representa $\mathrm{o}$ primeiro resultado;
$\mathrm{R} 2$ = representa $\mathrm{o}$ segundo resultado; $\mathrm{RF}=$ representa $\mathrm{o}$ resultado final (variação relativa ou redução percentual acumulada no período).

Sendo este cálculo realizado em todas as posições de ocupação, para o Brasil, Amapá e Tocantins. Para a interpretação do índice, primeiramente definiu-se os valores das pessoas ocupadas na semana de referência (mil pessoas) ao longo dos anos utilizados na pesquisa. Destarte, sua distribuição na categoria do emprego no trabalho principal, que passamos a chamar setores de ocupação ao longo do período estudado; e a variação relativa e ou redução percentual entre 2012 a 2019. Quanto maior a diferença entre as etapas analisadas pretende-se buscar entender as variações.

Adicionalmente, pretende-se observar o comportamento ao longo dos períodos nos Estados do Amapá e Tocantins, levando em consideração também os índices do Brasil como um todo.

A partir daí, é possível descrever o comportamento da distribuição da força de trabalho no Brasil nos anos de 2012 a 2019. Ademais, observar a variação permite acompanhar o desempenho dos Estados em específico sobre o total, além de identificar o perfil social e ocupacional no Brasil. 
Tabela 1. Pessoas de 14 anos ou mais ocupadas na semana de referência - Brasil - Amapá e Tocantins Distribuídas por setores de ocupação no Brasil - 2012 a 2019.

\begin{tabular}{|c|c|c|c|c|c|c|c|c|c|c|}
\hline \multicolumn{10}{|c|}{$\begin{array}{l}\text { Pessoas de } 14 \text { anos ou mais de idade, ocupadas na semana de referência - Brasil, Amapá e Tocantins, e média anual - por } \\
\text { posição na ocupação e categoria do emprego no trabalho principal }\end{array}$} & \multirow{3}{*}{$\begin{array}{l}\text { VARIAÇÃO } \\
\text { RELATIVA E OU } \\
\text { REDUÇÃO } \\
\text { PERCENTUAL } \\
\text { ENTRE } 2012 \text { È } \\
2019\end{array}$} \\
\hline \multicolumn{10}{|c|}{ Variável - Pessoas de 14 anos ou mais de idade, ocupadas na semana de referência (Mil pessoas) } & \\
\hline $\begin{array}{l}\text { Posição na ocupação e } \\
\text { categoria do emprego } \\
\text { no trabalho principal }\end{array}$ & $\begin{array}{l}\text { Brasil e } \\
\text { Unidade da } \\
\text { Federação }\end{array}$ & $\begin{array}{l}\text { ANUAL } \\
2012\end{array}$ & $\begin{array}{l}\text { ANUAL } \\
2013\end{array}$ & $\begin{array}{l}\text { ANUAL } \\
2014\end{array}$ & $\begin{array}{l}\text { ANUAL } \\
2015\end{array}$ & $\begin{array}{l}\text { ANUAL } \\
2016\end{array}$ & $\begin{array}{l}\text { ANUAL } \\
2017\end{array}$ & $\begin{array}{l}\text { ANUAL } \\
2018\end{array}$ & $\begin{array}{l}\text { ANUAL } \\
2019\end{array}$ & \\
\hline \multirow{3}{*}{ Total } & Brasil & 89064,25 & 90302 & 91637,5 & 91685 & 89974,75 & 90293,5 & 91570,5 & 93002 & $4,42 \%$ \\
\hline & Amapá & 280,25 & 289 & 308,75 & 307 & 298,25 & 301,5 & 300,75 & 323 & $15,25 \%$ \\
\hline & Tocantins & 605,5 & 603,5 & 628,25 & 616,75 & 610,5 & 604,5 & 635 & 637,6667 & $5,31 \%$ \\
\hline \multirow{3}{*}{$\begin{array}{l}\text { Empregado no setor } \\
\text { privado, exclusive } \\
\text { trabalhador doméstico } \\
\text { - sem carteira de } \\
\text { trabalho assinada }\end{array}$} & Brasil & 11022,25 & 10770 & 10312,75 & 10018,5 & 10087,5 & 10649,75 & 11133,25 & 11487,33 & $4,22 \%$ \\
\hline & Amapá & 25,75 & 28 & 26,5 & 28,75 & 27,25 & 29 & 34,25 & 32,33337 & 25,579 \\
\hline & Tocantins & 107,75 & 91,25 & 102,25 & 97,5 & 97 & 88,25 & 85,25 & 102,3333 & $-5,03 \%$ \\
\hline \multirow{3}{*}{$\begin{array}{l}\text { Trabalhador doméstico } \\
\text { - sem carteira de } \\
\text { trabalho assinada }\end{array}$} & Brasil & 4184 & 4115 & 4050,75 & 4097 & 4097,25 & 4288,25 & 4404,5 & 4450,667 & $6,37 \%$ \\
\hline & Amapá & 16,5 & 17,5 & 16,25 & 18 & 15 & 17 & 16,75 & 16,66667 & $1,01 \%$ \\
\hline & Tocantins & 36,75 & 35,5 & 34,75 & 33,25 & 34,5 & 36 & 44,25 & 42,33333 & 15,1996 \\
\hline \multirow{3}{*}{ Empregador sem CNPJ } & Brasil & - & - & - & - & 650,25 & 828,75 & 901,25 & 840,6667 & $29,28 \%$ \\
\hline & Amapá & - & - & - & - & 20,25 & 3 & 3,25 & 2,6666667 & $-86,83 \%$ \\
\hline & Tocantins & - & - & - & - & 4,5 & 4,25 & 6 & 6,333333 & $40,74 \%$ \\
\hline \multirow{3}{*}{$\begin{array}{l}\text { Conta própria sem } \\
\text { CNPJ }\end{array}$} & Brasil & - & - & - & - & 18116 & 18361 & 18749,25 & 19294,67 & $6,51 \%$ \\
\hline & Amapá & - & - & - & - & 22,25 & 90,5 & 86,5 & 106,6667 & $379,40 \%$ \\
\hline & Tocantins & - & - & - & - & 125 & 123,75 & 141,75 & 140 & $12 \%$ \\
\hline \multirow{3}{*}{$\begin{array}{l}\text { Trabalhador familiar } \\
\text { auxiliar }\end{array}$} & Brasil & 2772,5 & 2768,5 & 2603,75 & 2579,25 & 2104,5 & 2196,5 & 2173,25 & 2165,333 & $-21,90 \%$ \\
\hline & Amapá & 9,75 & 8,5 & 11,25 & 10,5 & 11,5 & 10,5 & 7,75 & 15 & $53,85 \%$ \\
\hline & Tocantins & 15,5 & 13,5 & 16 & 13,75 & 9,75 & 11,75 & 11 & 16 & $3,23 \%$ \\
\hline
\end{tabular}

Fonte: Elaboração dos autores, a partir dos microdados do PNAD (2012 a 2019).

\section{PENSANDO OS RESULTADOS BRASIL}

Com base na abordagem anteriormente apresentada, torna-se oportuno observar a variação da distribuição por setores de ocupação. Conforme plotado no Gráfico 1. Observa-se que a ocupação Empregador sem CNPJ e por Conta própria sem CNPJ entra no gráfico somente nos anos de 2016 a 2019, pois anteriormente a esta data estes setores não estavam no questionário do PNAD, as demais ocupações possuem pouca variação a ser destacada ao longo do período. Com uma queda perceptível no Empregado do setor privado, exclusive trabalhador doméstico - sem carteira de trabalho assinada no ano de 2015. Para Antunes (2018) é justamente entre os terceirizados que as condições de trabalho são as piores, pois esses trabalhadores acabam aceitando maiores jornadas de trabalho, maior rotatividade e menor acesso a benefícios.
Gráfico 1. Distribuição da população por setores de ocupação no Brasil - 2012 a 2019.

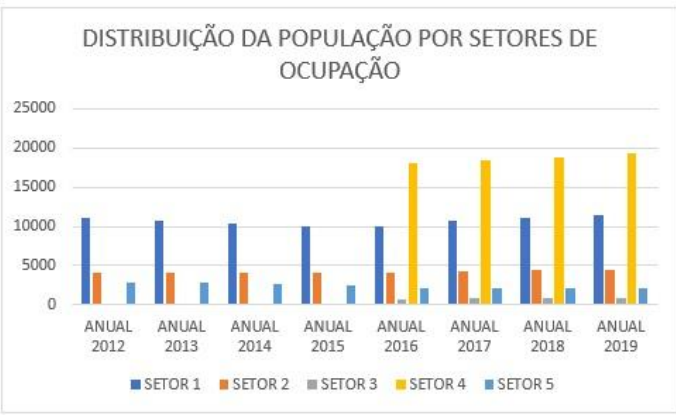

Fonte: Elaboração dos autores, a partir dos microdados do PNAD (2012 a 2019).

Setor 1. Empregado no setor privado, exclusive trabalhador doméstico - sem carteira de trabalho assinada; Setor 2. Trabalhador doméstico - sem carteira de trabalho assinada; Setor 3. Empregador sem CNPJ; Setor 4. Conta própria sem CNPJ; Setor 5. Trabalhador familiar auxiliar.

Destarte, os dados sugerem que quando passaram a fazer parte da pesquisa o Empregador sem CNPJ e o trabalhador por Conta própria sem CNPJ nos anos apresentados de 2012 a 2019 não contribuíram para alteração dos demais dados, contudo no ano de 
2019 percebe-se uma variação nos dados, pois em 2018 o Empregador sem CNPJ apresentava 901,25 (mil pessoas) e o trabalhador por Conta própria sem CNPJ 18749,25 (mil pessoas), já em 2019 passam a representar Empregador sem CNPJ apresentava 840,6667 (mil pessoas) e o trabalhador por Conta própria sem CNPJ 19294,67 (mil pessoas), representado uma alteração. De um lado, isso se deve ao fato das transformações econômicas que o Brasil vivenciou, e consequentemente devido a implementação das novas Leis; por outro lado, pode ser reflexo de uma acomodação dos profissionais buscando uma regularização da situação.

Em relação a variação relativa ou redução percentual, conforme pode ser visualizada no Gráfico 2, somente o Trabalhador familiar auxiliar registrou redução percentual ao longo do período analisado, embora em relação ao Brasil como um todo a variação tenha se apresentado positiva.

Gráfico 2. Variação relativa ou redução percentual por setores de ocupação no Brasil durante o período de 2012 a 2019.

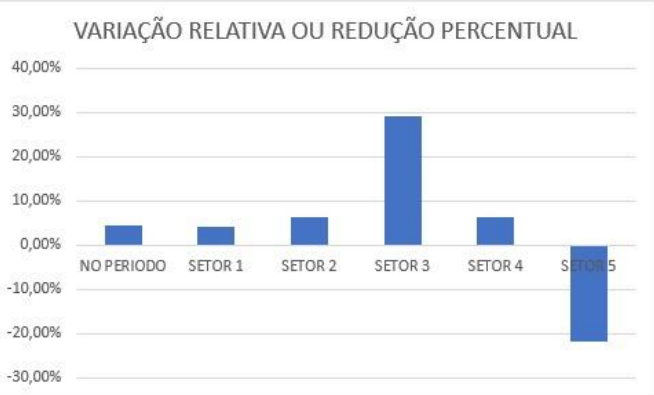

Fonte: Elaboração dos autores, a partir dos microdados do PNAD (período representado de 2012 a 2019).

Setor 1. Empregado no setor privado, exclusive trabalhador doméstico - sem carteira de trabalho assinada; Setor 2. Trabalhador doméstico - sem carteira de trabalho assinada; Setor 3. Empregador sem CNPJ; Setor 4. Conta própria sem CNPJ; Setor 5. Trabalhador familiar auxiliar.

As maiores variações são encontradas no setor de Empregados sem CNPJ com 29,28\% de variação relativa, e no setor Trabalhador familiar auxiliar com uma redução percentual de -21,28\% (negativa). Nesses

\footnotetext{
${ }^{2}$ Referencia utilizada pelo autor para a pessoa jurídica (PJ) que de acordo com o autor é apresentada falsamente como
}

setores, a redução percentual do setor 5 poderia justificar a variação relativa do setor 3 . No caso com a efetivação das novas regras, essa redução do setor 5 implica na variação relativa do setor 3 . Já setor 1 . Empregado no setor privado, exclusive trabalhador doméstico - sem carteira de trabalho assinada temos uma variação relativa de 4,22\% indicando perda de postos de trabalho formais.

Para Antunes (2018) apesar do mundo moderno advogar a favor da perda da relevância do trabalho no mundo contemporâneo, precisamos entender os desafios de sua nova morfologia, que possui um desenho multifacetado, consequência das mutações das últimas décadas. O que potencializa a tese da precarização das atividades de trabalho do período analisado, pois acresce o Setor 3, que está inserido nas atividades da MEI, que nas palavras de Antunes (2018) significa a ampliação da "pejotização". E quando analisada isoladamente a variação relativa do setor 1 , comparando com a 146 variação do Brasil como um todo que foi de $4,42 \%$ comprova-se a diminuição da capacidade de ofertas de vaga neste setor.

\section{PENSANDO OS RESULTADOS AMAPÁ X TOCANTINS}

No que se refere aos resultados isolados do Amapá e do Tocantins, os dados do Gráfico 3 mostram, a distribuição da população por setores de ocupação no Amapá. Neste sentido é conveniente destacar que as variações consideráveis são encontradas nos anos de 2017 a 2019 período de implantação das novas regras trabalhistas.

No Amapá em 2016 quando passaram a utilizar os setores 3 e 4 na pesquisa do PNAD os dados continuaram equilibrados, passando por alterações conjuntamente com a introdução das novas regras

um microempreendedor, trabalhador autônomo, e desta forma burlando os direitos trabalhistas. 
trabalhistas 2017, 2018 e 2019. O setor por Conta própria sem CNPJ é o que expõem alterações significativas, em 2017 apresentava 90,5 (mil pessoas) alocadas neste setor. Já em 2019 passa para 106,6667 (mil pessoas). As perdas são observadas no setor de Empregador sem CNPJ que em 2016 era 20,25 (mil pessoas) e, em 2019 passa para 2,666667 (mil pessoas), demonstrando uma redução acentuada tomando por base somente o período. Esta baixa pode ser explicada pelo fato do MEI beneficiar a pejotização (ANTUNES, 2018) na contratação dos trabalhadores, na verdade seria necessário aprofundar um estudo propriamente do Estado do Amapá.

Gráfico 3. Distribuição da população por setores de ocupação no Amapá - 2012 a 2019.

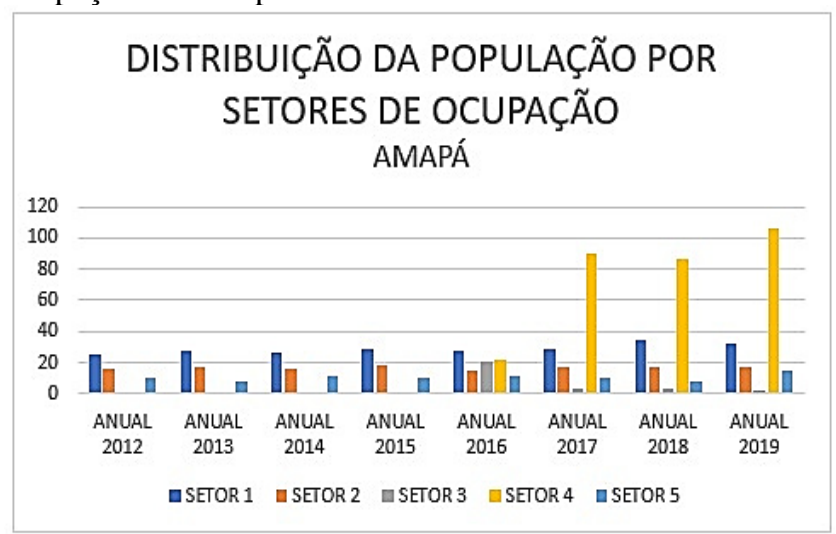

Fonte: Elaboração dos autores, a partir dos microdados do PNAD (2012 a 2019).

Setor 1. Empregado no setor privado, exclusive trabalhador doméstico - sem carteira de trabalho assinada; Setor 2. Trabalhador doméstico - sem carteira de trabalho assinada; Setor 3. Empregador sem CNPJ; Setor 4. Conta própria sem CNPJ; Setor 5. Trabalhador familiar auxiliar.

\section{Conforme Castro (2019) o PJ (Pessoa} Jurídica) é uma contratação que disfarça o vínculo empregatício, pois substitui a relação empresatrabalhador pela relação empresa-empresa, e devido a pluralidade de corpos disponíveis para o trabalho, invisibiliza essa equalização da força de trabalho dentro do capitalismo. Neste cenário, o elevado número de trabalhadores pejotizados, denuncia a situação do crescimento deste setor.

No que se refere a variação relativa ou redução percentual, comparando o Brasil ao Amapá, é possível observar no Gráfico 4 que o Amapá ao longo de todo o período analisado possui diferencial em relação ao Brasil como um todo. As maiores incidências podem ser encontradas em ordem decrescente nos setores 4, 3 e 5 quando comparadas com o Brasil como um todo.

Gráfico 4. Variação relativa ou redução percentual por setores de ocupação no Brasil e Amapá durante o período de 2012 a 2019.

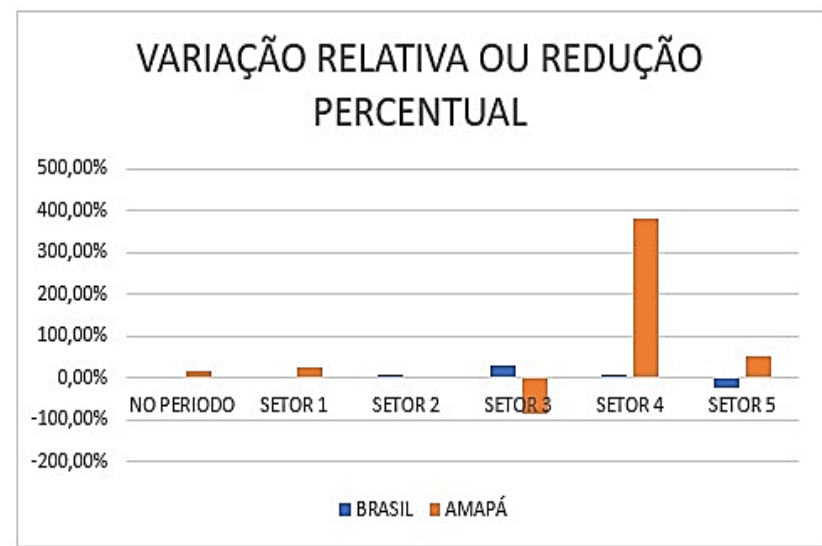

Fonte: Elaboração dos autores, a partir dos microdados do PNAD (período representado de 2012 a 2019).

Setor 1. Empregado no setor privado, exclusive trabalhador doméstico - sem carteira de trabalho assinada; Setor 2. Trabalhador doméstico - sem carteira de trabalho assinada; Setor 3. Empregador sem CNPJ; Setor 4. Conta própria sem CNPJ; Setor 5. Trabalhador familiar auxiliar.

Trabalhador por conta própria possui uma variação relativa de $379,40 \%$ ao passo que o Brasil no mesmo período analisado possui $6,51 \%$. O empregador sem CNPJ tem uma redução de percentual de $-86,83 \%$ ao passo que o Brasil apresentou uma variação relativa de $29,28 \%$. Já o trabalhador familiar no Amapá tem uma variação relativa de $53,85 \%$ ao passo que o Brasil apresentou na verdade uma redução percentual $-21,90 \%$. Esses resultados mostram que a dissimilitude entre o Brasil e o Amapá permite um aprofundamento mais minucioso para compreender tais alteridades. Tomando por base a posição geográfica, o ritmo de crescimento econômico, bem como a distribuição ocupacional por setores específicos na região.

Importante destacar que muitas vezes a única coisa que as mãos que vivem do trabalho possuem como moeda de troca são: o tempo, força física, e em certos casos conhecimento cultural, dependendo do 
nível de escolaridade do país estudado. Como falamos do Brasil o tempo é uma importante moeda de troca para esses trabalhadores, e sobre esse contexto, Cantor (2019) alerta, que até o tempo, foi expropriado de importantes setores pelo capitalismo, pois as pessoas mais pobres têm sido obrigadas a usá-lo permanentemente por meio dos dispositivos eletroeletrônicos da contemporaneidade.

No que se refere a distribuição da população por setores de ocupação no Tocantins, os dados do gráfico 5 mostram concentração no setor 4,1 e 2 , e menor participação nos setores 5 e 3 respectivamente. Porém, é oportuno enfatizar que independentemente da quantidade concentrada no setor por Conta Própria sem CNPJ e que mesmo com a implementação do MEI, o número de participantes concentra a maior parte da população ocupada do Tocantins, e este grupo continua representando as atividades que ao longo do tempo são chamadas informais.

Gráfico 5. Distribuição da população por setores de ocupação no Tocantins - 2012 a 2019.

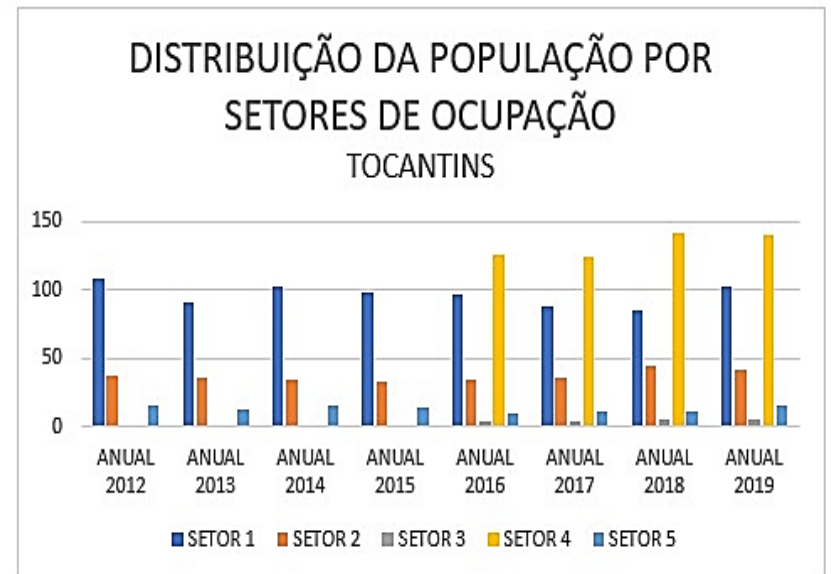

Fonte: Elaboração dos autores, a partir dos microdados do PNAD (período representado de 2012 a 2019).

Setor 1. Empregado no setor privado, exclusive trabalhador doméstico - sem carteira de trabalho assinada; Setor 2. Trabalhador doméstico - sem carteira de trabalho assinada; Setor 3. Empregador sem CNPJ; Setor 4. Conta própria sem CNPJ; Setor 5. Trabalhador familiar auxiliar.

No que se refere à variação relativa ou produção percentual do Estado do Tocantins comparado com o Brasil como um todo, é possível observar algumas diferenças pontuais. No gráfico 6 estão plotados os dados acerca da variação relativa que conforme observa-se, no Tocantins foi 5,31\%, ao passo que no Brasil foi de 4,42\%, logo no Tocantins a variação relativa foi $0,89 \%$ superior. Aprofundando a análise observa-se que no setor 1. Empregado no setor privado, exclusive trabalhador doméstico - sem carteira de trabalho assinada, enquanto o Brasil teve uma variação relativa de $4,22 \%$ o Estado do Tocantins teve uma redução percentual de $-5,03 \%, \log$ com as reformas trabalhistas é possível que no Tocantins esse desemprego será integrado ao sistema empregatício sob a forma de modelos de subemprego, pois conforme podemos observar o setor 2 . Trabalhador doméstico sem carteira de trabalho assinada $(6,37 \%$ Brasil 15,19\% Tocantins), o setor 3. empregador sem CNPJ (29,28\% Brasil - 40,74\% Tocantins), e o setor 4 . de Conta Própria sem CNPJ (6,51\% Brasil - 12\% Tocantins) foram os que mais cresceram, e em alguns casos mais que o dobro. Ademais, enquanto o Brasil reduziu o número de trabalhador familiar auxiliar 21,90\%, o Tocantins manteve-se com um índice de 148 $3,23 \%$ ao longo do período.

Gráfico 6. Variação relativa ou redução percentual por setores de ocupação no Brasil e Tocantins durante o período de 2012 a 2019.

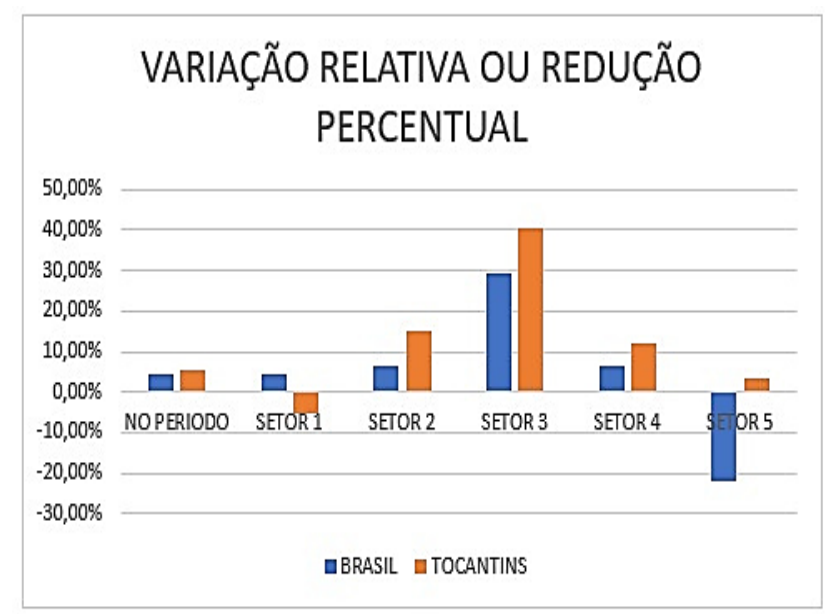

Fonte: Elaboração dos autores, a partir dos microdados do PNAD (período representado de 2012 a 2019).

Setor 1. Empregado no setor privado, exclusive trabalhador doméstico - sem carteira de trabalho assinada; Setor 2. Trabalhador doméstico - sem carteira de trabalho assinada; Setor 3. Empregador sem CNPJ; Setor 4. Conta própria sem CNPJ; Setor 5. Trabalhador familiar auxiliar.

No que se refere a variação relativa ou redução percentual é possível perceber a partir dos indicadores 
no Gráfico 7, tomando como base o Brasil, o Amapá e o Tocantins, o grande diferencial do comportamento do Estado do Amapá em relação aos demais, em todos os setores, mas com destaque para os setores 4 (Conta própria sem CNPJ), 3 (Empregador sem CNPJ) e 2 (Trabalhador doméstico - sem carteira de trabalho assinada), se consideramos que esses setores acentuam as ações da informalidade, é possível detectar no Amapá um grande bolsão da informalidade.

Gráfico 7. Variação relativa ou redução percentual por setores de ocupação no Brasil, Amapá e Tocantins durante o período de 2012 a 2019.

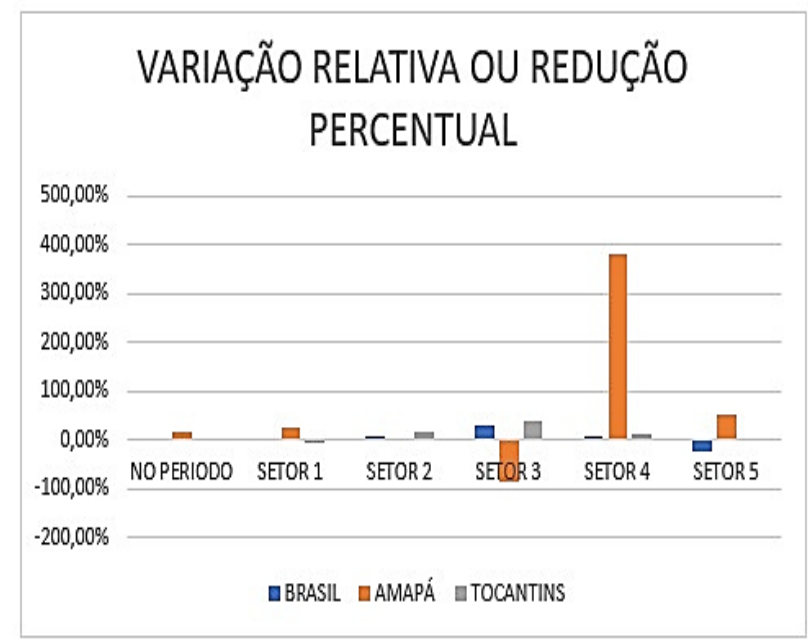

Fonte: Elaboração dos autores, a partir dos microdados do PNAD (período representado de 2012 a 2019).

Setor 1. Empregado no setor privado, exclusive trabalhador doméstico - sem carteira de trabalho assinada; Setor 2. Trabalhador doméstico - sem carteira de trabalho assinada; Setor 3. Empregador sem CNPJ; Setor 4. Conta própria sem CNPJ; Setor 5. Trabalhador familiar auxiliar.

Além disso, em todos os anos em observação, quando isolados e colocados lado a lado, o diferencial do Tocantins torna-se insignificante diante dos diferenciais do Amapá, um Estado da Região Norte do Brasil que merece mais atenção e aprofundamento nos estudos. Nesse contexto visualiza-se um quadro de retardo econômico bem como uma maior participação da informalidade nesta região. Dado que para Varela e Pereira (2019) é bem preocupante quando pensamos em desenvolvimento econômico de uma região. Para os autores desemprego e flexibilização são faces de uma mesma moeda, e atualmente estão sendo financiados com as reservas que deveriam servir como fundo de proteção para o envelhecimento digno, com saúde e qualidade. Eles explicam que a segurança social não evoluiu de um sistema assistencialista, mas de uma evolução natural, de um processo revolucionário que permitiu a proteção social, logo utilizar estas reservas antes da velhice, significa colocar em risco toda a situação econômica de um país e de uma população, que no caso do Brasil, serão os mais pobres e necessitados.

\section{CONSIDERAÇÕES FINAIS}

Este artigo procurou verificar as transformações ocorridas no mercado de trabalho formal e informal observadas ao longo dos anos 2012 a 2019, especialmente com a implementação das Leis $\mathrm{n}^{\mathrm{o}} 13.467 / 2017$ e $\mathrm{n}^{\mathrm{o}} 13.874 / 2019$. Os principais resultados mostram que não está ocorrendo troca setorial, ou seja, não há repasse de um setor para outro, por exemplo o setor 1 Empregado no setor privado, exclusive trabalhador doméstico - sem carteira de 149 trabalho assinada, não vem sendo esvaziado para ocupar o setor 4. Conta própria sem CNPJ. Contudo, o setor 3. Empregador sem CNPJ é o que possui a maior taxa de variação relativa e o setor 5 . Trabalhador familiar auxiliar o que possui a maior taxa de redução percentual, a nível Brasil.

Em relação a comparação entre os Estados do Amapá e Tocantins, observou-se um destaque diferencial em relação ao Brasil como um todo para o Estado do Amapá. No que diz respeito a distribuição da população por setores de ocupação ocorreu um esvaziamento do número de pessoas no setor 3 . Empregado sem CNPJ e um crescimento do setor 4. Conta própria sem CNPJ, isso comparando 2016, com 2017 a 2019. Quanto ao Tocantins os níveis da distribuição da população não diferem tanto se relacionado ao Brasil, com ligeiro acrescimento do setor 1. Empregado no setor privado, exclusive 
trabalhador doméstico - sem carteira de trabalho assinada, e 4. Conta própria sem CNPJ.

A alta variação relativa destaca-se no Amapá respectivamente no Setor 4. Conta própria sem CNPJ, cuja variação relativa é acima de $300 \%$, no setor 5 . Trabalhador familiar auxiliar, no qual o Brasil como um todo teve redução percentual e o Amapá uma variação relativa de mais de $50 \%$. Em relação ao setor 3. Empregador sem CNPJ, enquanto o Brasil possui variação relativa, o Estado do Amapá possui redução percentual de mais de $80 \%$, neste caso não pelo número obtido, mas pela lógica é possível afirmar que ocorre o esvaziamento do setor 3. Empregador sem CNPJ para o setor 4. Conta própria sem CNPJ e setor 5. Trabalhador familiar auxiliar.

A partir disso, mesmo com a implementação da Lei $\mathrm{n}^{\mathrm{o}} 13.467 / 2017$ e a lei $\mathrm{n}^{\mathrm{o}} 13.874 / 2019$, a princípio não houve esvaziamento de um setor de trabalho para o outro, a nível Brasil, devido a introdução das Leis. Todavia, o Estado do Amapá representa um diferencial que precisa de um estudo mais minucioso. Em suma, diante do cenário marcado pela formalidade e informalidade, esse estudo demonstrou que, mesmo com a implementação das novas Leis não ocorreu troca de posições se setores no mercado de trabalho. Isso significa que apesar da precarização das condições nas relações de trabalho, no Brasil como um todo o cenário mercadológico de trabalho continua o mesmo, embora o Estado do Amapá por meio dos seus dados tenha se destacado inversamente ao resultado do Brasil como um todo. Portanto, é necessário realizar um estudo de caso mais aprofundado no Estado do Amapá, de modo a verificar-se o que ocorre neste mercado de trabalho.

\section{REFERENCIAIS BIBLIOGRÁFICAS}

ANTUNES, R. OS SENTIDOS DO TRABALHO: ensaio sobre a afirmação e negação do trabalho. $2^{\mathrm{a}}$ ed. São Paulo, SP: Boitempo. 2009.
. O privilégio da servidão: o novo

proletariado de serviços na era digital. - 1. ed. São Paulo: Boitempo, 2018. (Mundo do trabalho).

BRASIL. LEI No 13.467, DE 11 DE NOVEMBRO

DE 2017. Disponível em<

http://www.planalto.gov.br/ccivil_03/_ato2015-

2018/2017/lei/l13467.htm> Acessado em: $22 / 10 / 2019$

\section{LEI No 13.874, DE 20 DE SETEMBRO}

DE 2019. Disponível em:<

http://www.planalto.gov.br/ccivil 03/ ato2019-

2022/2019/lei/L13874.htm> Acessado em:

$02 / 12 / 2019$.

\section{CANTOR, R. V. A EXPROPRIACCÃO DO}

TEMPO NO CAPITALISMO ATUAL. In:

ANTUNES, R. (Org.) RIQUEZA E MISÉRIA DO

TRABALHO NO BRASIL IV: trabalho digital, autogestão e expropriação da vida. 1 ed. São Paulo: Boitempo, 2019.

\section{CASTEL, R. AS METAMORFOSES DA}

QUESTÃO SOCIAL: Uma crônica do salário. $10^{\mathrm{a}}$ ed. Petrópolis, RJ: Vozes. 2012.

CASTRO, B. QUANDO GÊNERO REVELA

CLASSE: mulheres e flexibilidade no setor da tecnologia da informação. In: ANTUNES, R. (Org.) RIQUEZA E MISÉRIA DO TRABALHO NO

BRASIL IV: trabalho digital, autogestão e expropriação da vida. 1 ed. São Paulo: Boitempo, 2019.

CORSEUIL, C. H. L.; NERY, M. C.; ULYSSEA, G. Uma Análise Exploratória dos Efeitos da Política de Formalização dos Microempresários

Individuais. In: Barbosa Filho; Gabriel Ulyssea; Fernando Veloso. (Org.). Causas e Consequências da Informalidade no Brasil. 1ed.Rio de Janeiro: Elsevier 2016, v. 1, p. 209-236.

IBGE - Instituto Brasileiro de Geografia e estatística. Pesquisa Nacional por Amostra de Domicílio Contínua Trimestre Móvel - PNADC/M. Disponível em: < https://sidra.ibge.gov.br/pesquisa/pnadcm/tabelas $>$. Acesso em: 12/12/19.

LIMA, T. B. de; COSTA, M. S. TRABALHO

INFORMAL: uma revisão sistemática da literatura brasileira na área de Administração entre 2004 e 2013. CADERNOS EBAPE.BR (FGV), v. 2, p. $310,2016$.

NORONHA, E. G. INFORMAL, ILEGAL, INJUSTO: percepções de mercado de trabalho no 
Brasil. RBCS, São Paulo, Vol. 18, nº 53, p. 111-179, out. 2003.

OLIVEIRA, E. E. de. LEI DA LIBERDADE

ECONÔMICA: Diretrizes interpretativas da nova Lei e análise detalhada das mudanças no direito civil e no registros públicos. Diponível em:< http://centrodecomunicacao.com.br/cnr/2019-9\%20\%20Lei\%20da\%20Liberdade\%20Econo\%CC\%82mi ca\%20PDF.pdf> Acessado em: 03/01/2020.

POLANYI, K. A GRANDE TRANSFORMAÇÃO: A origem na nossa época. $2^{\mathrm{a}}$ ed. Rio de Janeiro, RJ: Compus. 2000.

RASLAN, F. O. SAPATARIA PANDORA: informalidade e desenvolvimento da indústria de calçados de Nova Serrana (MG). In: ANTUNES, R. (Org.) RIQUEZA E MISÉRIA DO TRABALHO NO BRASIL IV: trabalho digital, autogestão e expropriação da vida. 1 ed. São Paulo: Boitempo, 2019.

RODRIGUES-FILHO, L. F. O MERCADO SUCROALCOOLEIRO E AS MUTAÇÕES DO
TRABALHO: o fim do cortador de cana. In: ANTUNES, R. (Org.) RIQUEZA E MISÉRIA DO TRABALHO NO BRASIL IV: trabalho digital, autogestão e expropriação da vida. 1 ed. São Paulo: Boitempo, 2019.

SEBRAE. TUDO QUE VOCÊ PRECISA SABER SOBRE O MEI. Disponível em: <

https://www.sebrae.com.br/sites/PortalSebrae/sebraea z/o-que-e-ser-

mei,e0ba13074c0a3410VgnVCM1000003b74010aR CRD> Acessado em: 27/20/2020.

ULYSSEA, G. Informalidade no Mercado de Trabalho Brasileiro: uma resenha da literatura. Revista de Economia Política, v. 26, n.3, p., 2006.

VARELA, R.; PEREIRA, L. B. SEGURANÇA SOCIAL, TRABALHO E ESTADO EM PORTUGAL. In: ANTUNES, R. (Org.) RIQUEZA E MISÉRIA DO TRABALHO NO BRASIL IV: trabalho digital, autogestão e expropriação da vida. 1 ed. São Paulo: Boitempo, 2019. 